\title{
ENSINO DE PATRIMÔNIO POR MEIO DE SISTEMAS LÚDICOS
}

\author{
João Gonçalves Neto ${ }^{1}$
}

Paulo César Castral ${ }^{2}$

\begin{abstract}
RESUMO
Através de um sistema lúdico composto por modelos tridimensionais dobráveis em papel, busca-se levar a crianças de nove a quatorze anos questionamentos acerca de patrimônio cultural, enfatizando o patrimônio arquitetônico. Antes de iniciarem-se as aplicações desse sistema em escolas, procurouse evidenciar e entender alguns pontos pertinentes às questões patrimoniais, como: as influências mercadológicas sobre o patrimônio arquitetônico; os efeitos do turismo nas relações entre indivíduos e bens tombados; os fatores que contribuem para apropriação cultural; e, as razões de mantê-los. Entende-se que o tombamento auxilie a formação de uma identidade coletiva, uma vez que integra a memória de certa comunidade. Contudo, também, se percebem as perdas causadas pela lógica de mercado, as ressignificações proporcionadas pelo turismo e os efeitos disso sobre os integrantes da comunidade. Nesse estudo, a fazenda Santa Maria do Monjolinho, patrimônio tombado em 2007, foi utilizada como base de construção dos modelos lúdicos e, a partir deles, pretende-se mostrar como as relações sociais, presentes na construção, imprimem-se no espaço físico, permitindo a discussão do tema pelas crianças, visando a melhor formação do cidadão
\end{abstract}

PALAVRAS-CHAVE: Modelos Dobráveis. Ensino. Patrimônio Arquitetônico.

\section{PLAYFUL SYSTEM THROUGH HERITAGE EDUCATION}

\begin{abstract}
Through a ludical system compound by tridimensional foldable paper models, it is expected to lead children (between the ages of nine and fourteen years old) questionings about cultural heritage, with emphasis in architectonic heritage. Before starting the aplication of this system in schools, it was intended to show and understand some relevant issues about heritage, as: how market influences architectonic heritage; tourism effects on the relationship between people and protected items; the points which contribute to cultural apropriation; and, the reasons which justify keeping it. Protecting

\footnotetext{
${ }^{1}$ Arquitetura e Urbanismo, Estudante de Graduação no IAU_USP, joao.goncalves.neto@usp.br

${ }^{2}$ Arquitetura e Urbanismo, Professor Doutor no IAU_USP, pcastral@gmail.com
} 
Revista Nacional de

Gerenciamento de Cidades

some cultural element helps the formation of a coletive identity since it integrates its memory. But it is also known the losses caused by the market logic, the ressignifications proposed by tourism and how it affects the comunity. The process of making the ludical models is based on 'fazenda Santa Maria do Monjolinho', heritage protected since 2007, these models intend elucidate how social relationships are shown in physical space allowing this subject to be discussed by children, trying to improve citizens formation.

KEY-WORDS: Foldable Models. Teaching. Architectonic Heritage.

\title{
SISTEMA JUGUETÓN TRAVÉS DE LA EDUCACIÓN DEL PATRIMONIO
}

\begin{abstract}
RESUMEN
Por medio de un sistema lúdico compuesto por modelos tridimensionales doblegables en papel, se busca llevar a los niños de nueve a catorce años cuestionamientos acerca del patrimonio cultural, enfatizándose el patrimonio arquitectónico. Antes de que se inicien las aplicaciones de ese sistema en escuelas, se busca evidenciar y entender algunos puntos pertinentes a las cuestiones patrimoniales, como: las influencias del mercado sobre el patrimonio arquitectónico; los efectos del turismo en las relaciones entre individuos y bienes declarados como patrimonio histórico; los factores que contribuyen para apropiación cultural; $y$, las razones por mantenerlos. Se entiende que el inmueble declarado como patrimonio histórico auxilie a la formación de una identidad colectiva, a la vez que integra la memoria de cierta comunidad. Además, también, se pueden percibir perdidas causadas por la lógica del mercado, las resignificaciones proporcionadas por el turismo y los efectos de eso sobre los integrantes de la comunidad. En este estudio, la hacienda "Santa Maria do Monjolinho", declarada patrimonio histórico en el 2007, fue utilizada como base de construcción de los modelos lúdicos y, a partir de ellos, se pretende mostrar como las relaciones sociales, presentes en la construcción, se imprimen en el espacio físico, permitiendo la discusión del tema por los niños, buscando con eso una mejor formación del ciudadano.
\end{abstract}

PALABRAS-CLAVE: Modelos Plegables. Enseñanza. Patrimonio Arquitectónico

\section{INTRODUÇÃO}

A palavra patrimônio está ligada às posses e às propriedades de alguém. Ao adicionarem-se a ela os adjetivos mais recorrentes (histórico, cultural, arquitetônico, artístico) a palavra patrimônio passa por uma requalificação, atraindo para si novos valores e significados.

Em um primeiro momento é importante salientar que entende-se por patrimônio cultural os objetos físicos tombados e os bens imateriais registrados por 
Revista Nacional de

Gerenciamento de Cidades

orgãos competentes. Considera-se que o patrimônio cultural seja uma nomenclatura generalizante, que se refira ao patrimônio histórico, artístico, musical, entre outros. Nesse trabalho, a principal abordagem é sobre o patrimônio arquitetônico, adotandose como a base de estudos a confecção de modelos tridimensionais dobráveis da fazenda Santa Maria do Monjolinho, tombada pelo Conselho de Defesa do Patrimônio Histórico, Arqueológico, Artístico e Turístico (CONDEPHAAT).

Procura-se em geral, por meio do tombamento, proporcionar a conservação de um edifício, por entender que ele carregue signos e significados relevantes, o que Ihe confere importância histórica, política, artística, arquitetônica. Essa importância, a priori, é relativa apenas ao meio onde ele está inserido, porém, o processo patrimonialização (Jeudy, 2002), atribuirá significados e finalidades além dos interesses daquela comunidade. Pode-se perceber a presença desse processo nas ações relativas ao turismo, por meio das quais o patrimônio arquitetônico perde os significados que o conecta com a identidade do meio onde está, para se converter em mercadoria.

Como já foi tema de debate por vários autores3, uma das características que define o patrimônio arquitetônico é a dualidade. O edifício tombado, mesmo que privado, tem caráter público. Esse mesmo edifício é um registro do passado locado no presente. Ou, seguindo o raciocínio anterior, o bem é tombado por sua importância em determinado local, mas após o tombamento atribuem-lhe importância tão além de seu meio, que o local onde está inserido se torna irrelevante. São ambiguidades que merecem reflexão e questionamentos da sociedade, já que a afeta de maneira geral, mesmo que indiretamente.

Outro ponto relevante na discussão de patrimônio cultural são as ideologias que o definem. Um edifício é testemunha de inúmeras interações sociais, sob seu teto se definem inúmeras relações sociais e, por meio dele, incontáveis fatos sociais ocorrem, contudo, tombar um edifício é selecionar quais dessas histórias que serão recontadas. Quando se tomba uma fazenda, apesar da presença gritante das

${ }^{3}$ Françoise Choay (2000); Antônio Arantes (2006); Maria Tereza Duarte Paes (2009) 


\section{Revista Nacional de}

Gerenciamento de Cidades

senzalas, a história é contada, em sua maioria, sob o ponto de vista do ex-senhor de escravos. Apagam-se os episódios indesejados, deslegitimiza-se toda a luta de um povo através da criação de um passado irreal, porém vendável. As ideologias que permeiam o patrimônio cultural, além de favorecer grupos hegemônicos, estão intrinsecamente relacionadas à lógica de mercado, ao fluxo de capital e à valorização financeira do edifício.

Apesar dessa realidade, os processos de patrimonialização estão aumentando consideravelmente (Jeudy, 2003) desde o fim do século XX, e, hoje, não se pode desvincular desenvolvimento e conservação (Troitiño Vinuesa, 1998). Nesse contexto surge a necessidade dos debates públicos sobre o patrimônio cultural, seus significados e suas implicações. Entendendo-se o papel ativo da criança no meio onde vive, procura-se levar esses questionamentos e informações a ela de forma que possa ser conduzida a um pensamento crítico sobre o tema, afim de que, quando adulta, seja uma cidadã consciente.

\section{OBJETIVOS}

O objetivo desse estudo é proporcionar à criança o acesso a informação sobre o patrimônio cultural por meio de modelos tridimensionais dobráveis afim de gerar pensamentos críticos acerca do assunto, despertando sentimentos de pertencimento e responsabilidade social sobre o meio que habita. Para isso, entende-se a necessidade de compreender aquilo que a sociedade considera como patrimônio cultural. Procura-se, então, entender o papel desse objeto em seu meio e as relações de poder a ele vinculadas.

\section{METODOLOGIA}


Revista Nacional de

Gerenciamento de Cidades

O estudo foi dividido em três etapas: pesquisa bibliográfica, construção dos modelos dobráveis tridimensionais e aplicação desses em escolas.

A base teórica abordou três temas distintos: um breve estudo sobre ensino, que serviu de introdução para o ensino através de jogos; uma análise sobre o conceito de jogos, seus significados e o que representam; e, o estudo sobre questões patrimoniais, relacionadas à influência do turismo, do mercado e de ideologias hegemônicas sobre patrimônio.

Para a criação dos modelos tridimensionais dobráveis escolheu-se a fazenda Santa Maria do Monjolinho, tombada pelo Conselho de Defesa do Patrimônio Histórico, Arqueológico, Artístico e Turístico (CONDEPHAAT) em 2007. Os modelos foram elaborados a partir das plantas e cortes dos edifícios componentes dessa fazenda. São doze modelos impressos em papel A4 com marcações para vincos e cortes, além de representação das respectivas fachadas.

A etapa final, referente à aplicação dos modelos em escolas, até a conclusão deste artigo, está em processo. Basicamente, esta etapa tem o objetivo de, através de um sistema lúdico, criar um sistemas de contingências que funcionem como reforçadores efetivos a crianças de 9 a 12 anos, de forma a estimular 0 interesse delas ao tema.

\section{RESULTADOS}

Entendendo-se que patrimônio cultural seja o conjunto de símbolos e signos que caracteriza determinado grupo de pessoas, pode-se atribuir-lhe duas funções principais: utilizá-lo afim de corroborar com a manutenção da identidade de determinado grupo, legitimando seus símbolos e signos de maneira a empoderarIhe; ou, seguir o caminho inverso, construindo uma nova identidade, a partir de elementos de outros grupos. As duas formas estão relacionadas ao poder, no primeiro caso, há permissão, no segundo, imposição. 


\section{Revista Nacional de}

O uso de símbolos e signos está vinculado à história humana. Choay (2000) apresenta três fatos que caracterizam diferentes abordagens desses usos: os atálidas e os romanos preservavam objetos gregos do período clássico e helenístico, pois estes serviriam de 'modelo' a ser seguido; no século XIV, Petrarca atribuiu aos edifícios antigos o caráter educativo, por meio da construção, se entendia a realidade que ela foi concebida e desenvolvida; e, Alberti (século XV), que conferia ao edifício o caráter de documento, como se fosse o registro físico daquilo que os historiadores escreveram.

Esses exemplos têm como objetivo mostrar que, apesar dessas discussões não se referirem ao patrimônio cultural, se referem ao cerne dele que são os símbolos e significados conferidos às edificações por determinada sociedade. Atualmente, algumas características de um objeto podem torná-lo passível de tombamento, como está na Constituição Brasileira de 1988

Art. 216. Constituem patrimônio cultural brasileiro os bens de natureza material e imaterial, tomados individualmente ou em conjunto, portadores de referência à identidade, à ação, à memória dos diferentes grupos formadores da sociedade brasileira, nos quais se incluem:

I - as formas de expressão;

II - os modos de criar, fazer e viver;

III - as criações científicas, artísticas e tecnológicas;

IV - as obras, objetos, documentos, edificações e demais espaços destinados às manifestações artístico-culturais;

$\mathrm{V}$ - os conjuntos urbanos e sítios de valor histórico, paisagístico, artístico, arqueológico, paleontológico, ecológico e científico;

$\S 1^{\circ}$ O poder público, com a colaboração da comunidade, promoverá e protegerá o patrimônio cultural brasileiro, por meio de inventários, registros, vigilância, tombamento e desapropriação, e de outras formas de acautelamento e preservação.

§ 2ํ Cabem à administração pública, na forma da lei, a gestão da documentação governamental e as providências para franquear sua consulta e quantos dela necessitem.

§ 3ำ A lei estabelecerá incentivos para a produção e o conhecimento de bens e valores culturais.

§ 4ํㅡㅇ Os danos e ameaças ao patrimônio cultural serão punidos, na forma da lei. 
$\S 5^{\circ}$ Ficam tombados todos os documentos e os sítios detentores de reminiscência históricas dos antigos quilombos

(Texto consolidado até a Emenda Constitucional no 28 de 25 de maio de 2000)

Segundo a Carta Europeia do Patrimônio Arquitetônico, adotada pelo Comitê dos Ministros do Conselho da Europa, em 26 de setembro de 1975, e promulgada no Congresso sobre o Patrimônio Arquitetônico Europeu, realizado em Amsterdã, de 21 a 25 de outubro de 1975, o patrimônio arquitetônico é um bem com significados espirituais, culturais, econômicos e sociais de valores insubstituíveis. E, quais seriam esses valores mencionados, senão aquilo que o edifício representa? Logo, tendo-se a Constituição e a Carta Europeia do Patrimônio Arquitetônico como base, percebese que é o significado atribuído ao objeto a característica essencial no processo de tombamento, pois ele está relacionado com a identidade e com a memória de determinado grupo social.

São os signos e significados dado aos objetos combinados ao contexto histórico, político e social que criam a ideia de apropriação. Determinado grupo aprende a se comportar perante determinado objeto a partir de relações afetivas, da educação e de políticas públicas. Se os acontecimentos relacionados ao objeto tiverem implicações positivas sobre os indivíduos, aumentam-se as chances deles se apropriarem desse objeto.

Essa relação do grupo com o objeto mostra que, aquilo que é considerado como patrimônio cultural é uma construção social e política, historicamente localizada. Partindo-se daí, pode-se questionar quanto dessa construção é permitida e quanto ela é imposta. Sentimentos ufanistas, por exemplo, são formas de proporcionar unidade social em governos fascistas, caracterizando uma ação impositiva; enquanto, por outro lado, os grafites passam por períodos de permissão, estimulando a expressão legítima de um grupo social por meio de um ato cultural.

A apropriação de um patrimônio arquitetônico por uma comunidade, no 


\section{Revista Nacional de}

entanto, é um ponto ambíguo. Como a comunidade, um sujeito público, pode se apropriar de um edifício, muitas vezes, um elemento privado? Como equilibrar universos antagônicos? A resposta para tal questão muitas vezes agrava problemas de distribuição socio-espacial, de forma que, um bem tombado, que deveria ser um bem coletivo, acessível a todos, muitas vezes serve de pretexto para segregação econômica.

Quando se trata da relação do patrimônio arquitetônico com o turismo levantam-se, ao menos, duas principais contradições: a relação afetiva com o edifício e o valor econômico a ele relacionado; e, o limiar caracterizado pelas mudanças que determinada construção pode sofrer para se adequar à lógica de mercado, sem perder sua identidade. Essas questões estão relacionadas ao que Choay (2000) aponta

[o] vasto público dos indivíduos para os quais a visita aos monumentos não é um fim em si mesmo, para aqueles que, individualmente, esperam do patrimônio histórico mais que uma distração - esperam dele à alegria do conhecimento histórico e aos prazeres da arte. Esse público é em geral enganado em massa pela indústria patrimonial, que -temos de admitir -, na esteira da evolução das sociedades industriais avançadas, tende a vender-lhe ilusões à guisa dos valores prometidos. (CHOAY, 2000, p. 228)

Nesse sentido, impõem-se histórias parcialmente, ou erroneamente, contadas para o turista comprar determinado produto. O patrimônio perde seus significados prévios e passa a ser uma mercadoria. Choay considera que "o valor memorial e afetivo que o patrimônio cultural carrega consigo é suprimido pelo valor de entretenimento que a indústria patrimonial lhe confere" (CHOAY, 2000, p.252). Geralmente a valorização do patrimônio de uma região é acompanhada por gentryfication, especulações financeiras e imobiliárias de forma que, mais uma vez, a comunidade que deveria ser beneficiada pelas políticas de patrimonialização, são afastadas do objeto apropriado. Luchiari (2005) destaca a responsabilidade da 
Revista Nacional de

Gerenciamento de Cidades

atividade turística nesses processo, que além de contribuir com ele, pode orientar sua condução.

A atual valorização do patrimônio arquitetônico, segundo Paes (2009), legitima a mercantilização da cultura, que se torna um bem distintivo de classes. Esse fato pode ser percebido pelas relações de fetishismo com o patrimônio cultural, em que as aparências superficiais adquirem mais importância do que significados subjacentes. Para surtir melhor efeito, adiciona-se ao processo natural de ressemantização do espaço, a lógica mercadológica, o que contribui para a criação de uma passado ilusório, criado apenas em prol do lucro.

Um grupo politicamente hegemônico se serve da divulgação de uma ideologia, entendida como um conjunto de idéias articuladas, para manter as estruturas sociais rígidas. A situação do patrimônio deve ser analisada a partir dessas ideologias, seus objetivos e suas razões. Se o patrimônio cultural pode ser usado para modelar um conjunto de comportamentos, para criar histórias que legitimem a permanência de um grupo no poder, ou até mesmo para justificar preconceitos, aquilo que é considerado patrimônio cultural deve passar por constantes reflexões afim de se analisar o que se está valorizando.

Em um prédio, a valorização se relaciona aos seus usos passados e presentes, aos seus moradores, aos funcionários e a possíveis elementos presentes em seu domínio. São as imagens enfatizadas que irão compor a construção simbólica do local e, apesar desse processo excluir a diversidade de relações existentes no passado, como aponta Paes (2009), cabe ao cidadão perceber que a história de um patrimônio é apenas uma versão.

Nesse sentido, as ações que definem a Educação Patrimonial podem ser consideradas de grande importância. Somente por meio de uma aproximação entre o sujeito social e o patrimônio, que o representa culturalmente, mediada pela informação e problematização é que uma nova geração de cidadãos críticos poderá se formar. Horta (1999, p.06) considera a Educação Patrimonial "um instrumento de 
Revista Nacional de

Gerenciamento de Cidades

alfabetização cultural", prevenindo a manutenção de uma historiografia dos virtuosos.

A versão costumeiramente escolhida é aquela que se adequada aos padrões de beleza, relacionadas ao luxo, a riqueza, e a opulência. Características que especialistas em publicidade e marketing transformam em produtos de consumo. O patrimônio se esvazia de significados relevantes para a cultura de um povo e passa a ser um meio para o enriquecimento individual. Destacando-se apenas as riquezas geradas por tal situação, consegue-se suprimir, ou esconder, as falhas sociais, de forma a desdobrar-se em segregações socio-econômicas, fato visível no espaço físico da cidade.

É no espaço físico da cidade que o debate sobre o patrimônio arquitetônico tem mais peso. Na paisagem urbana estão impressas as relações sociais, com suas as dinâmicas e seu simbolismo e, é nesse meio, que um prédio tombado se localiza, por vezes de forma deslocada. Esse estranhamento relaciona-se ao fato de que, como aponta Troitiño Vinuesa (1998), o território é resultado da comunidade que o habita.

O território, assim, passa constantemente por processos de ressemantização e reinterpretação, incidindo na constante reorganização dos usos e ocupações dos espaços urbanos. O ponto não é impedir esse processo em prol do patrimônio arquitetônico, mas analisá-lo e entender o que significam as mudanças e o que as ocasiona.

Tendo-se tal conhecimento, o processo de planejamento urbano se faz mas eficiente, assim como questões de gestão urbana. Deve-se considerar também o conceito de sustentabilidade proposto no relatório de Brundtland (1987) que entende que o desenvolvimento sustentável seja aquele que "satisfaz as necessidades básicas humanas contemporâneas, sem causar prejuízo para as gerações futuras" .

Essa relação da comunidade com o território auxilia na construção do sentimento de pertença, proporcionando a criação de uma identidade coletiva. A 
Revista Nacional de

Gerenciamento de Cidades

metamorfose urbana é um processo comum, por isso Jeudy considera que a cidade é antropófaga, 'canibaliza tudo, inclusive sua própria imagem' (JEUDY, 2005, p. 92). Se a identidade coletiva se faz presente e forte, esse processo de mudança se dá de forma mais proveitosa, ainda mais se considerar, como Choay aponta, que "indivíduos e sociedades não podem preservar e desenvolver sua identidade senão pela duração e pela memória" (CHOAY, 2000, pp. 112-113)

A necessidade de se contribuir para um pensar crítico da comunidade acerca de tais questões motivou a criação de modelos tridimensionais por meio de dobraduras em papel, colaborando assim com o ensino patrimonial por meio de atividades lúdicas. No caso analisado, foram feitos 12 modelos baseados na Fazenda Santa Maria do Monjolinho, localizada em São Carlos, estado de São Paulo. A fazenda foi tombada pelo Conselho de Defesa do Patrimônio Histórico, Arqueológico, Artístico e Turístico (CONDEPHAAT) como patrimônio histórico, cultural e educacional.

A história da fazenda Santa Maria do Monjolinho inicia-se em 1850. Sua ascensão econômica é derivação do período em que a produção cafeeira estava em maior destaque no século XIX. Em 1886, os donos da fazenda iniciam a construção do sobrado sede, que serviria de estadia para D. Pedro II, quando de sua vinda à São Carlos para inauguração da ferrovia. Theodoro, um dos donos da fazenda, almejava o título de Barão, por isso o interesse na presença do imperador. O projeto da sede da fazenda é de autoria do engenheiro italiano David Casinelli, baseando-se em palacetes europeus. O sobrado apresenta traços urbanos, mesmo sendo construído em uma área rural. Afim de se destacar a opulência e a extravagância do período em questão, os materiais de construção, como cimento, vitrais e afrescos foram trazidos da Europa.

Além do sobrado, outros edifícios foram construídos na mesma época, partilhando de diretrizes projetuais, como: a casa do administrador, que possui um sino, elemento determinante no ritmo de trabalho; a tulha, com a roda d'água, 
Revista Nacional de

Gerenciamento de Cidades

responsável pela energia utilizada na beneficiação do café; a senzala, construção composta por dois compartimentos sem janelas - após a abolição da escravidão a construção serviu de moradia aos imigrantes; a casa do "capitão do mato"; e, a estação Monjolinho que se destinava ao transporte de pessoas e bens, como: café e leite, produções de destaque na região. Atualmente, a estação passou por um processo de remodelçaão do espaço, sendo usada como um restaurante.

No início do século XX, a propriedade é passada para Cândido de Souza Campos e Zuleika Malta, junto à propriedade vieram todo o mobiliário e pertences dos ex-proprietários, que foram conservados, sendo expostos na sede da fazenda, após seu tombamento em 2007.

Do produto desse tombamento, foram feitos doze modelos tridimensionais dobráveis, sendo os de maior destaque: a Sede, a Tulha, a Senzala e a Estação Monjolinho. O objetivo da criação desses modelos é facilitar uma nova abordagem sobre o bem tombado, permitindo ao usuário uma nova compreensão, que sirva de base para a apropriação do patrimônio.

Espera-se, por meio dos modelos, elucidar as dinâmicas sócio-espaciais. Mostrando a localização de cada elemento, pode-se abrir discussões sobre como as relações de poder se imprimem no espaço. Percebe-se isso, por exemplo, quando se aponta a implantação da sede da fazenda em um ponto mais alto da fazenda, quando comparada às outras construções, ou a proximidade entre a senzala e a casa do capitão do mato.

Outro ponto esperado é a compreensão de como a imagem da fazenda é transmitida, como os usuários entendem-na e como pode-se levantar pontos mais relevantes desse patrimônio para a sociedade. Pode-se destacar tal processo nas questões ligadas às políticas escravocratas e como ela tem influência nos discursos racistas atuais.

Esse exemplo, da história dos escravos, é baseado na falta de informações sobre o assunto durante a visita ao lugar. Não salientar isso é negar a importância 
Revista Nacional de

Gerenciamento de Cidades

dessas pessoas e de sua história, uma vez que pessoas escravizadas foram a principal mão-de-obra durante um grande período de tempo. Entende-se que, trabalhando melhor tais questões, eleva-se a importância do patrimônio arquitetônico. Este passa, assim, a servir de base para a discussão de problemas atuais, não cristalizando e glorificando seu passado, mas relacionando-o com a sociedade atual.

A ação educativa aqui apresenta significa buscar desconstruir a imagem criada pelo processo de mercantilização. Procura-se reverter o quadro atual dos "turistas" que lá visitam, apontando para uma visão crítica do patrimônio. Entende-se que tais questões não comovem a maior parte do público, sendo mais fácil e conveniente para os proprietários criarem ideias de opulência e luxo vinculadas à construção. Educar as crianças, nesse caso, contribui para a formação de uma nova geração mais informada e consciente de seu papel na sociedade.

O caráter lúdico desses objetos proporciona uma nova relação da criança com a fazenda, no caso. Apesar de ainda não terem sido aplicados em crianças, os modelos procuram se encaixar nos critérios que Campagne (1989), considera serem fundamentais para o melhor aproveitamento do brinquedo no ambiente escolar, sendo eles: o Valor Experimental - o objeto deve permitir a exploração e a manipulação do mesmo; o Valor de Estruturação - o objeto deve dar suporte à construção da personalidade infantil (entendendo, nesse caso, como o patrimônio influencia a noção de identidade cultural); o Valor de Relação - o objeto deve servir como ponte entre a criança e os outros; e, o Valor Lúdico - o objeto deve servir como suporte de ações lúdicas.

\section{CONCLUSÃO}

Durante esse estudo, percebeu-se que o patrimônio cultural, de forma geral, são conjuntos de signos e símbolos construídos socialmente, geralmente 
Revista Nacional de

Gerenciamento de Cidades

contribuindo com grupos hegemônicos. As relações sociais se mantém impressas nos patrimônios arquitetônicos, muitas vezes mascaradas por discursos construídos com objetivo de justificar determinado comportamento atual ou apenas visando a venda de produtos vinculados aos edifícios.

Compreender-se o que essas construções ideológicas representam é abrirse caminho a questões de interesse público, visto que questionam a importância de cada elemento, o que sua preservação infere e, consequentemente, a melhor forma de conservá-lo afim de transmitir determinada imagem. A questão da imagem do objeto que será divulgada é de extrema importância. Tendo-se que a imparcialidade do discurso é impossível, deve-se baseá-lo em pontos que contribuam para o desenvolvimento social, não o glorificando, mas usando-o de base para discussões de questões atuais.

Quando a educação infantil aborda temas de patrimônio cultural, busca-se: ensinar a criança a procurar referências de suas ações nos fatos passados; desconstruir a imagem de patrimônio como algo 'sagrado' e atribuir-lhe papel mais ativo na comunidade onde está inserido; e, possibilitar, através do conhecimento sobre a construção, a apropriação cultural do edifício pelas crianças, levantando-se questões pertinentes de forma responsável.

Entende-se, por fim, que levar esses objetivos a educação escolar contribui para a formação de cidadãos mais preparados. O indivíduo terá como componente de sua identidade, elementos de sua comunidade, fato que contribui de forma positiva para sentimentos de pertencimento em seu meio e responsabilidade sobre esse.

\section{REFERÊNCIAS}

ARANTES, A. O Patrimônio Cultural e seus Usos: a Dimensão Urbana. Habitus, Goiânia, v. 4, n.1, p. 425-435, jan./jun. 2006. 


\section{Revista Nacional de}

Gerenciamento de Cidades

CHOAY, F. A Alegoria do Patrimônio. São Paulo: Unesp, 2000. 383p.

HORTA, Maria de Lourdes P., GRUNBERG, Evelina, MONTEIRO, Adriane Queiroz. Guia Básico de Educação Patrimonial. Brasília: Instituto do Patrimônio Histórico e Artístico Nacional, Museu Imperial. 1999

JEUDY, H. P. Maquinaria Patrimonial. Rua (Revista de Arquitetura e Urbanismo), Salvador, PPG-AU Universidade Federal da Bahia, volume 8, 2003, p. 74-79 Disponível em:

www.portalseer.ufba.br/index.php/rua/article/ download/3234/2352 Acessado em 2 de Jul. de 2015.

JEUDY, H. P. O Espelho da Cidade. Rio de Janeiro: Casa da Palavra, 2005. 160p.

KISHIMOTO, T. M. O Jogo e a Educação Infantil. São Paulo: Cengage Lerning, 1994. 63p.

LUCHIARI, M. T. D. P. A Reinvenção do Patrimônio Arquitetônico no Consumo das Cidades. GEOUSP - Espaço e Tempo, São Paulo, n. 17, p. 95 - 105, 2005.

PAES, M. T. D. Patrimônio cultural, turismo e identidades territoriais: um olhar geográfico. In: Bartholo, R.; Sansolo, D. G.; Bursztyn, I. (orgs.). Turismo de Base Comunitária: Diversidade de Olhares e Experiências Brasileiras. Rio de Janeiro: Letra e Imagem, 2009. p. 162-176.

TROITIÑO VINUESA, M.A. Patrimonio arquitectónico, cultura y territorio. Ciudades: Revista del Instituto Universitario de Urbanística de la Universidad de Valladolid, Valladolid, no 4, 1998, p. 95-104. Disponível em: http://dialnet.unirioja.es/servlet/articulo?codigo=2241051 Acessado em 25 de Mai. de 2015. 